\title{
ENSINO SUPERIOR NO CONTEXTO DA PANDEMIA DA COVID-19: UM RELATO ANALÍTICO
}

\author{
HIGHER EDUCATION IN THE CONTEXT OF THE PANDEMIC OF \\ COVID-19: AN ANALYTICAL REPORT
}

\section{EDUCACIÓN SUPERIOR EN EL CONTEXTO DE LA PANDEMIA DE COVID-19: UN INFORME ANALÍTICO}

Lucila Pesce

Universidade Federal de São Paulo - Brasil

Ana Maria Di Grado Hessel

Pontifícia Universidade Católica de São Paulo - Brasil

\begin{abstract}
Resumo: O presente artigo tem por objetivo refletir acerca das dificuldades apresentadas ao ensino superior e seus enfrentamentos, considerando-se o cenário da pandemia da COVID-19. No que diz respeito à abordagem metodológica, o artigo situa-se como um relato analítico das ações educacionais desenvolvidas em duas universidades sediadas no estado de São Paulo: uma pública e uma comunitária. O quadro teórico do relato analítico apoia-se em um intertexto entre o conceito de ação comunicativa em Habermas e dialogismo em Bakhtin. Com base neste marco teórico, o artigo reflete sobre a hegemônica racionalidade instrumental que ampara boa parte das ações educacionais no ensino superior brasileiro, ainda mais recrudescida no contexto da supracitada pandemia. Por meio dela, da racionalidade instrumental, o mundo da vida dos atores sociais diretamente envolvidos nos processos formativos (estudantes, professores, gestores e técnicos educacionais) é colonizado pelo sistema; no caso, o sistema educacional. À contramão desta racionalidade hegemônica, tão cara ao capital, o presente artigo relata algumas ações educacionais desenvolvidas no seio das duas universidades, com base na premissa dialógica, em respeito ao mundo da vida dos professores e estudantes participantes das aludidas ações educacionais.
\end{abstract}

Palavras-chave: Educação; Pandemia da COVID-19, Racionalidade Instrumental.

\begin{abstract}
This article reflects on the difficulties presented to higher education and their confrontations, considering the scenario of the pandemic of COVID-19. Regarding to the methodological approach, the article is classified as an analytical report of the educational actions developed at two universities in São Paulo state, Brazil: a public and a communitarian one. The theoretical framework of the analytical report is based on an intertext between the concept of Communicative Action (Habermas) and Dialogism (Bakhtin). Based on this theoretical framework the article reflects on the hegemonic instrumental rationality which supports a good part of the educational actions in Brazilian higher education, even more so in the context of the pandemic. Through the instrumental rationality, the world of life of the social actors directly involved in the educational processes (students, teachers, managers and educational technicians) is colonized by the system, in this case, the educational system. In opposition
\end{abstract}


to this hegemonic rationality, imbricated to capital, this article reports some educational actions developed by these two universities, based on dialogic premise, in attention to the teachers and students' world of life that participate in the reported educational actions.

Keywords: Education; COVID-19 Pandemic, Instrumental Rationality.

Resumen: Este artículo tiene como objetivo reflexionar sobre las dificultades que presenta la educación superior y sus enfrentamientos, considerando el escenario de la pandemia de COVID-19. En relación con el enfoque metodológico, el artículo se caracteriza como un relato analítico de las acciones educativas desarrolladas en dos universidades en São Paulo: una pública y otra comunitaria. El marco teórico del informe analítico se basa en dos conceptos: acción comunicativa en Habermas y dialogismo en Bakhtin. Con base en este marco teórico, el artículo reflexiona sobre la racionalidad instrumental hegemónica que apoya buena parte de las acciones educativas en la educación superior brasileña, más aún en el contexto de la pandemia mencionada. A través de ella, a través de la racionalidad instrumental, el mundo de la vida de los actores sociales directamente involucrados en los procesos de formación (estudiantes, docentes, directivos y técnicos educativos) es colonizado por el sistema; en este caso, el sistema educativo. Contrariamente a esta racionalidad hegemónica, tan cara al capital, este artículo relata algunas acciones educacionales desarrolladas dentro de las dos universidades, que buscan fundamentarse en la premisa dialógica, con respeto al mundo de la vida de los docentes y estudiantes participantes en las acciones educativas mencionadas.

Palabras clave: Educación; Pandemia COVID-19, Racionalidad Instrumental.

\section{Introdução}

Desde 2020, a sociedade global vem enfrentando inúmeras dificuldades em face do advento da pandemia da COVID-19. A aludida pandemia tem imposto grandes desafios a serem enfrentados pelas organizações societárias, nos campos sanitário, da saúde, da economia, da segurança pública, da cultura, e em inúmeras áreas, dentre as quais o presente artigo se ocupa dos desdobramentos da supracitada pandemia na educação, em especial, no ensino superior.

Com base nos apontamentos da UNESCO (2020), Dias e Pinto (2020) sinalizam a necessidade de se pensar em uma articulação adequada entre ensino remoto e presencial. E o fazem, elencando inúmeras atribulações que têm sido enfrentadas pelas instituições de ensino. Em suas palavras: 
[...] muitos no Brasil não têm acesso a computadores, celulares ou à Internet de qualidade - realidade constatada pelas secretarias de Educação de Estados e municípios no atual momento - e um número considerável alto de professores precisou aprender a utilizar as plataformas digitais, inserir atividades online, avaliar os estudantes a distância e produzir e inserir nas plataformas material que ajude o aluno a entender os conteúdos, além das usuais aulas gravadas e online. Na pandemia, grande parte das escolas e das universidades estão fazendo o possível para garantir o uso das ferramentas digitais, mas sem terem o tempo hábil para testá-las ou capacitar o corpo docente e técnico-administrativo para utilizá-las corretamente.

$[\ldots]$

Há ainda outros obstáculos graves, especialmente para alunos e professores mais empobrecidos, muitos deles localizados na periferia das grandes cidades ou na zona rural. Faltam computadores, aparelhos de telefonia móvel, software e Internet de boa qualidade, recursos imprescindíveis para um $\mathrm{EaD}$ que resulte em aprendizagem (DIAS e PINTO, 2020, p. 546).

Levanto em consideração a problemática anunciada por Dias e Pinto (2020), a discussão acerca dos desafios impostos ao ensino superior no contexto da pandemia da COVID-19 desenvolve-se a partir de um relato analítico das ações educacionais desenvolvidas por duas professoras, autoras deste texto, atuantes em duas universidades sediadas no estado de São Paulo: uma pública federal (doravante Universidade A) e uma comunitária de caráter confessional (doravante Universidade B).

O relato analítico de algumas das ações que têm sido desenvolvidas por ambas as universidades se ampara na premissa dialógica, por meio de dois conceitos: dialogismo bakhtiniano e ação comunicativa habermasiana. Partamos, pois, ao quadro teórico que baliza ambos os relatos analíticos anunciados adiante.

\section{Habermas e a ação comunicativa}

Intelectual da segunda geração da Escola de Frankfurt, o filósofo e sociólogo Jürgen Habermas - apoiado em Edmund Husserl, Max Weber, Martin Heidegger, György Lukács, Theodore Adorno e Max Horkheimer, entre outros - elabora um diagnóstico dos descaminhos da razão moderna, como o desencantamento, a alienação e a massificação da consciência (FREITAG, 2005).

Habermas (1987) ampara-se em Weber, para refletir sobre a racionalização social; em Adorno (1987), sobre a crise da modernidade; em Lukács (1987), sobre a coisificação da razão humana. Com base nesses conceitos, Habermas (2002; 2003) persegue uma alternativa aos conflitos da sociedade contemporânea, ao forjar a Teoria da Ação Comunicativa (2002; 2003).

Habermas $(1990 ; 1998 ; 1999)$ propõe-se a contribuir para a reconstrução do projeto social fundamentado no cultivo da razão comunicativa, tendo em vista a fecundidade da linguagem para a autorreflexão e para o entendimento mútuo. Ao fazê-lo, o filósofo reitera que 
a racionalidade comunicativa - expressa nas relações cotidianas - opõe-se à racionalidade instrumental. Para o filósofo, contrariamente ao agir comunicativo, que se baseia nas relações intersubjetivas voltadas à emancipação humana, o agir estratégico funda-se na razão instrumental, para fins de controle e dominação.

Ao discorrer sobre o estado de mal-estar das sociedades modernas, pela subserviência do mundo da vida e das instituições culturais a mecanismos de integração sistêmica como dinheiro e poder, Habermas (2005, p. 26) adverte:

\begin{abstract}
Os grupos excluídos ou empurrados para a margem não possuem poder de veto, uma vez que representam uma minoria desmembrada do processo de produção. E parece que o padrão que se impôs, em nível internacional, entre as metrópoles e a periferia subdesenvolvida se repete no interior das sociedades capitalistas mais desenvolvidas: porquanto o processo de autorreprodução dos poderes estabelecidos depende cada vez menos do trabalho e da vontade de cooperação dos empobrecidos e deserdados.
\end{abstract}

Daí a relevância de se colocar o mundo da vida no palco da história. Para o filósofo, é no mundo da vida que se realiza o agir comunicativo, de natureza dialógica e expresso por meio de argumentos proferidos, livre de coação.

Sobre o entendimento mútuo, com base argumentativa, Habermas $(1987 ; 1998 ; 2002)$ salienta que tal consenso é sempre provisório, por ser concebido no seio das relações intersubjetivas eivadas de historicidade. E ele - o consenso a ser perseguido - deve ocorrer, levando-se em consideração o mundo da vida: pano de fundo das vivências dos sujeitos sociais.

Sob a égide desse entendimento, Habermas expressa sua positividade em relação ao conceito amplo de racionalidade, que integra o paradigma da consciência e o paradigma da comunicação $(1987 ; 1998 ; 2002)$, por meio do qual o agir comunicativo exerce papel fulcral na construção de formas de organização social mais solidárias e emancipadoras.

A crítica de Habermas $(2002 ; 2003)$ à racionalidade instrumental (inerente ao sistema e voltada aos fins de controle e dominação) e a defesa do agir comunicativo (integrante do mundo da vida e voltado ao entendimento mútuo sempre provisório) consubstanciam-se como elementos fundantes para se pensar a educação, notadamente agora, no contexto da pandemia da COVID-19, em que os processos formativos têm se valido exclusivamente da linguagem hipermídia veiculada na cibercultura (SANTAELLA, 2004). Isso porque sabemos que, a despeito dos esforços olvidados por instituições de ensino superior comprometidas com a “qualidade social” (CONAE, 2018) dos processos formativos por elas ofertados, não são poucas as instituições educacionais com iniciativas de uso dos dispositivos e interfaces digitais voltadas à economia de custo (BARRETO, 2001; PESCE, 2010). 


\section{Bakhtin e o Dialogismo}

Em estudos anteriores (PESCE, 2010), havíamos considerado a fecundidade da arquitetura teórica de Bakhtin, com destaque para o conceito de dialogismo (1997b). Para Bakhtin (1997a), que rege sua visão teórica com base no Materialismo Histórico, os seres humanos são historicamente datados e se constituem mutuamente por meio de práticas sociais, notadamente a linguagem. Em especial porque é por meio dela, da linguagem, que as negociações de sentido são engendradas pelos enunciadores.

Bakhtin (1997a) anuncia a característica socioideológica da língua, mediante a dialética relação entre os sistemas da língua e seus enunciadores. O conceito bakhtiniano de compreensão responsiva ativa (BAKTHIN, 2010) ampara-se na ideia de que o conhecimento é construído na interação do sujeito com o objeto - mediada pelo outro, por meio da linguagem - e do sujeito com outros sujeitos.

Ao considerar a natureza dinâmica, relacional, responsiva e ativa da compreensão, Bakhtin (1997b; 2010) destaca que os falantes se consubstanciam como sujeitos sociais no contexto das relações sociais. Em seu dizer: “a compreensão de uma fala viva, de um enunciado vivo é sempre acompanhada de uma atitude responsiva ativa... [...] compreender é cotejar com outros textos e pensar num contexto novo (no meu contexto, no contexto contemporâneo, no contexto futuro)" (BAKHTIN, 1997b, p. 290).

Em diversas obras, Bakhtin $(1997 \mathrm{a} ; 1997 \mathrm{~b} ; 2010)$ salienta o quanto os processos de subjetivação erguem-se em meio a práticas sociais, sobretudo os enunciados. Os indivíduos constituem-se no cotidiano, na enunciação, no dialogismo. Em outras palavras, para o filósofo da linguagem, a consciência não se constitui fora do corpo. Muito ao contrário, a consciência é material e se constitui na interação do sujeito com o contexto cultural a que pertence. Nesse sentido, as contra palavras de cada um dos enunciadores viabilizam a construção de suas respectivas identidades.

Na verdade, a língua não se transmite; ela dura e perdura sob a forma de um processo evolutivo contínuo. Os indivíduos não recebem a língua pronta para ser usada; eles penetram na corrente da comunicação verbal; ou melhor, somente quando mergulham nessa corrente é que sua consciência desperta e começa a operar (BAKHTIN, 1997a, p. 108).

O conceito bakhtiniano de dialogismo (BAKHTIN, 1997a; 1997b) ampara-se na ideia de que o individual e o social se engendram mutuamente. É por essa razão que, para ele, a unidade do mundo é polifônica e polissêmica por excelência, por erguer-se em meio às múltiplas vozes e aos múltiplos significados atribuídos pelos enunciadores. 
Ao anunciar o dialogismo como elemento fundante da relação entre os sujeitos sociais, Bakhtin (1997a) reitera a ideia de que a linguagem verbal é constitutiva dos sujeitos e da linguagem por eles enunciada. Nesse movimento, o filósofo da linguagem sinaliza que a consciência dos sujeitos se ergue em meio a signos internalizados, por meio de práticas sociais, históricas e ideológicas.

Para o estudioso, cada fala insere-se, em devir, na cadeia de enunciados, respondendo, pelas contra palavras, questões anteriores e prevendo interpretações. Em seu dizer: “o monólogo pretende ser a última palavra [...] O diálogo inconcluso é a única forma adequada de expressão verbal de uma vida autêntica" (BAKHTIN, 1997b, p. 334).

A arquitetura teórica bakhtiniana situa a interação verbal como lócus primeiro da produção de ideologia e a linguagem, como instância basilar à leitura crítica da realidade, uma vez que a consciência se organiza e se desenvolve por meio do dialogismo (PESCE, 2010).

A natureza dialógica da linguagem exprime o caráter inovador do enfoque bakhtiniano, a seu tempo e até os dias de hoje.

\section{Dialogismo bakhtiniano e ação comunicativa habermasiana: possíveis aproximações}

Em meio às especificidades teóricas de ambos os intelectuais, é possível encontrar alguns pontos de convergência, no que diz respeito à concepção de ser humano, de organização societária e do papel da linguagem nos modos de subjetivação, nos processos constitutivos da consciência emancipada e de práticas sociais autorais (PESCE, 2010).

Ambos os teóricos se ocupam de refletir sobre os descaminhos da racionalidade hegemônica nas atuais organizações societárias, apontando a fecundidade da linguagem para um projeto de reconstrução social, com base no entendimento mútuo e na emancipação dos sujeitos. Ao fazê-lo, Habermas, com amparo na Filosofia e da Sociologia, e Bakhtin, sob enfoque da Filosofia da Linguagem, intentam novas formas de se recuperar os sujeitos sociais, em que pese a atrofia da competência comunicativa, na atualidade, subserviente à racionalidade instrumental (PESCE, 2007).

Bakhtin concebe a unidade do mundo como polifônica e polissêmica, assim como Habermas forja o conceito de ação comunicativa, situando as múltiplas vozes dos sujeitos sociais no palco da história. Esse entendimento é basilar ao conceito de docência autoral (PESCE, 2007; VELOSO e BONILLA, 2018). Na docência autoral exercida na cultura digital, o professor planeja, desenvolve, divulga, implementa e oferece de forma autônoma seus cursos. Não participa como executor de um script de autoria alheia, mas sim como membro de um 
trabalho integrado com equipes multiprofissionais (PESCE, 2007). No contexto da cultura digital, a autoria se expressa em um movimento de interlocução, nas relações e nas interações que sustentam a rede (VELOSO e BONILLA, 2018). Considerando o princípio dialógico do ato da criação, manifestado nas relações com o outro a com a cultura, Veloso e Bonilla (2018) anunciam que os dispositivos e interfaces digitais, situados como artefatos culturais, podem apontar possibilidades interativas e potencialidades de criação. Mas, para que isso aconteça, é preciso que a vertente de uso da linguagem hipermídia da cibercultura (SANTAELLA, 2004) esteja comprometida com a premissa dialógica, como ensinam Habermas (1990, 1998, 1999, 2002, 2003) e Bakhtin (1997a, 1997b, 2010).

Nesse sentido, Bakhtin (1997a) destaca a constituição dos sujeitos sociais na materialidade histórica do cotidiano, do mundo vivido, no qual se engendram relações sociais dialógicas, polissêmicas, polifônicas e inconclusas em devir. Habermas assume como desafio maior a elaboração de um projeto de reconstrução social capaz de reabilitar o mundo da vida no seio das estruturas societárias. Ao fazê-lo, salienta a relevância do mundo da vida para os processos de constituição de identidades descolonizadas do sistema. Bakhtin o faz, sinalizando o valor da práxis para o entendimento da linguagem como prática social. Nesse movimento, ambos os intelectuais ressaltam o valor dos processos linguísticos argumentativos e dialógicos aos modos de subjetivação eivados de autoria. Daí a importância das proposições teóricas de ambos os intelectuais, para se desvelar as contradições atinentes à utilização dos dispositivos e interfaces digitais no ensino superior, voltada à economia de custo.

O conceito de compreensão ativa em Bakhtin (1997b) e o conceito de ação comunicativa em Habermas (1987) são engendrados, à guisa de se encontrar formas de superação das condições históricas alienantes, pela construção do entendimento mútuo, em um movimento em que os sujeitos sociais se posicionem livremente, em face dos argumentos proferidos por outrem (PESCE, 2007).

Como se pode observar, o dialogismo bakhtiniano e a ação comunicativa habermasiana parecem ser particularmente fecundos para subsidiar teoricamente o relato analítico a seguir, afeito a ações desenvolvidas por duas professoras universitárias, em tempos de pandemia da COVID-19.

\section{Relato analítico - Universidade A (pública federal)}

Em meio às múltiplas adversidades impostas pela pandemia da COVID-19, a Universidade A, uma das universidades públicas federais sediadas no estado de São Paulo, logo 
se mobilizou para ações conjuntas de enfrentamento das atribulações emanadas da aludida pandemia, levando em consideração as normativas legais (BRASIL, 2020 - Parecer CNE/CP n. $\left.{ }^{\circ} 5\right)$.

Atenta à necessidade de se pensar na prevenção e redução dos altos níveis de ansiedade, depressão e estresse emanados do confinamento imposto aos estudantes no período da quarentena (MAIA; DIAS, 2020), a Universidade A mobilizou muitos setores e impulsionou uma série de reuniões, em diversas instâncias, como as câmaras de graduação e de pósgraduação de todos os campi da instituição, a Pró-reitoria de Assuntos Estudantis (PRAE), a Pró-reitoria de Graduação (PROGRAD), a Pró-reitoria de Pós-Graduação e Pesquisa (PRPGP), o Conselho Administrativo (CA), o Conselho Universitário (CONSU), dentre outras.

Uma das decisões do CONSU foi elaborar um levantamento das necessidades dos estudantes (hardware, software, acesso à internet, local e horas disponíveis para o estudo etc.), com atenção especial aos que vivem em condições de maior vulnerabilidade, para que pudessem ser providenciadas medidas para facilitar o acesso desses discentes aos dispositivos digitais, para participar das aulas em regime de ADE (Atividades Domiciliares Emergenciais). A denominação ADE foi eleita para explicitar que a atuação remota é de caráter emergencial, com vigência restrita aos tempos da pandemia. Traçado o diagnóstico, os diversos cursos iniciaram o planejamento das ações a serem desenvolvidas em modo ADE, por ocasião da retomada do primeiro semestre letivo de 2020. Também foram ouvidos docentes e técnicos da Universidade.

Outra decisão do CONSU foi por retirar o sistema de avaliação por atribuição de nota e substituí-lo pelo sistema de avaliação por conceito: "cumprido" ou "não cumprido". O CONSU achou por bem proceder desse modo, durante a pandemia, para minimizar o possível ônus aos estudantes, já que a classificação discente para obtenção de bolsas (institucionais e das agências de fomento) vinculadas a programas como PIPIC (Programa Institucional de Bolsas de Iniciação Científica), PIBIT (Programa Institucional de Bolsas de Iniciação em Desenvolvimento Tecnológico e Inovação), PIBID (Programa Institucional de Bolsas de Iniciação à Docência), Monitoria, dentre outros, baseia-se na aferição de notas.

Em virtude da necessidade de se proceder a diversos ajustes, a Universidade - que havia interrompido as atividades presenciais do $1^{\circ}$. semestre letivo em 17 de março de 2020 - acabou por retomá-lo em 3 de agosto nos campi de Guarulhos, São José dos Campos, Osasco e Baixada Santista, à exceção do campus São Paulo, que o fez em 6 de julho.

No âmbito do curso de Pedagogia, após 45 dias de aulas em regime de ADE os licenciandos foram solicitados a responder a um questionário, em que pudessem revelar as 
condições materiais de que dispunham para cursar as disciplinas, avaliar o trabalho desenvolvido e apontar suas maiores objeções. Todos estes dados foram compilados pela coordenação de curso e discutidos em reunião de colegiado, como vistas a subsidiar as ações em andamento (relativas à finalização do primeiro semestre letivo) e as ações a serem desenvolvidas, quando do início do segundo semestre letivo de 2020, previsto para a segunda quinzena de novembro.

No que diz respeito às aulas ofertadas pela primeira autora do presente artigo, tanto na graduação quanto no Programa de Pós-Graduação em Educação (doutorado e mestrado acadêmico), as ações formativas junto aos universitários têm sido desenvolvidas mediante encontros síncronos semanais, com duração de uma hora e meia na graduação e duas horas, na pós-graduação. Seguindo orientações do CONSU, os encontros síncronos têm sido sempre gravados, de modo a garantir que o estudante que não tenha podido participar das interações em tempo real, possa fazê-lo a posteriori.

Além das rodas de conversa nos encontros síncronos, as disciplinas da graduação e da pós-graduação também têm contado com o apoio de salas virtuais, em que estão previstos repositórios (de textos, vídeos, lives, links dos encontros em tempo real etc.) e recursos de interação. A premissa dialógica tem acompanhado as ações formativas dessas aulas, considerando que o registro das interações no Ambiente Virtual de Aprendizagem (AVA) pode contribuir para os processos formativos, sob enfoque dialógico, com destaque para três aspectos (PESCE, 2012):

a) o mapeamento do percurso dos discentes, pela professora, de modo a facilitar o processo de avaliação processual;

b) a meta reflexão do estudante, mediante o revisitar do registro das suas produções e por meio de recursos como o memorial reflexivo ou o diário de bordo, em que ele possa se situar como "sujeito responsivo" (BAKHTIN, 1997b, 2010) da sua aprendizagem, revendo e adensando a reflexão sobre seu percurso formativo;

c) o fortalecimento de ações colaborativas entre os universitários, por meio de ambientes de discussão, como fóruns e chats.

No caso da disciplina eletiva "Inclusão digital como fator de inclusão social: questões para a educação básica" - ofertada aos licenciandos - houve consenso entre a professora e os estudantes sobre a necessidade de se discutir o momento pelo qual todos estão passando, em função da pandemia da COVID-19. Assim sendo, além dos textos e vídeos previstos no plano 
de curso, a cada encontro síncrono tem havido discussão sobre a temática "educação em tempos de pandemia", a partir de lives correlatas. Dentre elas destacam-se:

a) Educação a distância: universidade e pandemia. Primeira live da ANPED - Associação Nacional de Pós-Graduação e Pesquisa em Educação, no contexto da pandemia.

Profa. Dra. Edmea Santos (UFRRJ) e Profa. Dra. Geovana Lunardi (Presidente da ANPED).

b) Ensino híbrido, ensino remoto e educação à distância: tensões e perspectivas. Integrando o Congresso Acadêmico da Universidade A.

Profa. Dra. Adriana Rocha Bruno (UNIRIO), Profa. Dra. Raquel Goulart Barreto (UERJ), Profa. Ms. Sílvia Nogueira (SEE-SP).

c) Cultura digital, racionalidade comunicativa e empoderamento dos sujeitos sociais em tempos de pandemia. Integrando o ciclo de debates do grupo de pesquisa FORTEC (UNEB)

Profa. Dra. Lucila Pesce (UNIFESP)

d) Educação em tempos de COVID: o que precisam professores e estudantes para sobreviver. Integrando o ciclo de debates do grupo de pesquisa FORTEC (UNEB) Profa. Dra. Sara Dias-Trindade (Universidade de Coimbra)

e) Entre raiz e a flor tempo e espaço: docências hoje. Integrando o ciclo de debates do grupo Educações em Rede.

Profa. Dra. Adriana Rocha Bruno (UNIRIO) e Profa. Dra. Diene Mello (UEL)

f) Educação e formação em tempos e cenários de pandemia. Integrando o ciclo de encontros "Educação e formação", do grupo de pesquisa PRODOC (UNIFESP).

Profa. Dra. Magali Silvestre e Profa. Dra. Verilda S. Kluth (UNIFESP)

g) Ensino remoto em tempos de pandemia: visão da Pedagogia histórico-crítica. Integrando as ações da Associação de Docentes da Universidade do Estado da Bahia - ADUNEB. Prof. Dr. Demerval Saviani (UNICAMP).

h) Os tempos sombrios que nos rondam: Arendt e a atualidade Prof. Dr. José Sérgio Fonseca de Carvalho (USP)

i) Educação em tempos de pandemia da COVID-19: impactos na saúde mental / emocional Prof. Dr. José Leon Crochíc (USP / Unifesp)

Oportuno esclarecer que as duas últimas lives circularam restritamente, por terem sido especialmente desenvolvidas para os licenciandos que cursavam o conjunto das disciplinas 
eletivas ofertadas no primeiro semestre do curso de Pedagogia, não sendo, portanto, objeto de discussão exclusiva dos estudantes da eletiva ofertada pela primeira autora deste texto.

A decisão por acrescentar lives sobre educação em tempos de pandemia para discutir acerca de temática tão candente ampara-se no conceito bakhtiniano de "excedente de visão" (BAKHTIN, 2010). Isso porque, a partir da discussão das aludidas lives, a cada encontro os estudantes têm tido a possibilidade de refletir sobre os obstáculos a enfrentar, levando em consideração não somente suas experiências, como também aspectos abordados por especialistas no campo e vivências relatadas por outrem. Com isso, o processo meta reflexivo sobre o seu percurso formativo em tempos de pandemia têm ocorrido a partir de uma perspectiva ampliada de alteridade.

Com vistas ao enfrentamento conjunto, nestes tempos de pandemia, a Pró-reitoria de Graduação (PROGRAD) da Universidade tem fortalecido a "Rede de Apoio Docente" (RAD), mediante encontros síncronos, toda quinta-feira, às 13 horas. Os encontros, intitulados "Ciclo de Debates sobre Articulações de Ensino e Aprendizagem e as Tecnologias Digitais" são de natureza diversa: debates conceituais, discussões de natureza prática, troca de experiências etc. A cada semana há um tema a ser tratado, à guisa de formar os docentes para atuar remotamente, da melhor maneira possível. Em tais encontros, os "Vídeos do Ciclo de Debates da PROGRAD" ficam gravados e disponíveis para serem assistidos a posteriori, em uma sala virtual da RAD. Nela, os docentes da Universidade têm acesso a:

a) informações gerais sobre o ensino remoto;

b) normativas legais e institucionais sobre o ensino remoto;

c) informações sobre direitos autorais e uso de imagem;

d) segurança no uso dos recursos;

e) simulações de aulas práticas remotas;

f) diversos materiais dos cursos de formação da Universidade, inclusive os que dizem respeito à configuração dos AVA Moodle e Google Classroom, pelo professor;

g) tutoriais sobre o uso da sala de aula virtual;

h) recursos voltados a encontros síncronos por videoconferência (Rede Nacional de Ensino e Pesquisa - RNP, Google Meet etc.);

i) ferramentas para avaliação de aprendizagem;

j) dispositivos voltados a ações interativas e colaborativas, dentre outros aspectos que integram os processos formativos dos docentes da Universidade. 
Além da troca de experiências e de saberes afeitos aos dispositivos e interfaces que podem ser utilizados pela Universidade nas ações desenvolvidas em regime de ADE, essa rede tem fortalecido os vínculos dos professores, intra campus e inter campi e, por conseguinte, o sentimento de pertença ao grupo e à Universidade.

Obviamente, são muitas as tribulações que têm se apresentado diuturnamente aos estudantes. Infortúnios múltiplos, dentre os quais se destacam:

a) os de natureza operacional: afeitos à fluência digital;

b) os vinculados às condições materiais: acesso à Internet, hardware e software disponíveis, horário e local para estudo etc.;

c) os relacionados à saúde mental: em decorrência do isolamento social, de perdas financeiras, de perdas de entes queridos, do cuidado com familiares e amigos que contraíram a doença etc.

Alguns docentes também têm se defrontado com situações semelhantes, além da necessidade de se qualificar da melhor maneira possível e com celeridade, para atuar remotamente. Estas e outras adversidades têm, por vezes, causado nos estudantes e nos docentes universitários um sentimento de mal-estar, mas certamente a situação haveria de ser pior, se as ações não estivessem sendo pautadas pela premissa dialógica, na perspectiva bakhtiniana e habermasiana.

\section{Relato analítico - Universidade B (comunitária de caráter confessional)}

Quando as aulas presenciais foram suspensas, em março de 2020, em função da pandemia da COVID-19, os professores e alunos da Universidade B, uma universidade comunitária de caráter confessional de São Paulo, foram tomados pelo sentimento de perplexidade. Logo na primeira semana do ocorrido, todos ficaram desnorteados e aos poucos foram vislumbrando algumas possibilidades para dar prosseguimento às atividades didático pedagógicas.

A universidade B já contava com o suporte da plataforma Moodle - Modular Object Oriented Dynamic Learning Environment. Trata-se de um AVA (Ambiente Virtual de Aprendizagem) de código aberto e de uso popular, pela gratuidade. Funciona como uma sala de aula online, na qual os docentes podem colocar material didático e propor atividades interativas. Grande parte da comunidade acadêmica já fazia uso da plataforma para registrar suas aulas, para oferecer conteúdos midiáticos, tutoriais e documentos diversificados, para o uso de fóruns, para enviar e receber tarefas, para divulgar links e facilitar acesso aos endereços 
da web. Parte das disciplinas fazia esse uso, vinculado à oferta percentual de $20 \%$ da carga horária no formato remoto (BRASIL, 2019).

Além do Moodle, a universidade também já possuía um contrato com a Microsoft para oferecer gratuitamente os serviços do OFFICE 365 à toda comunidade de estudantes, aos professores e funcionários. No início da pandemia, a plataforma Teams, que integra o pacote de serviços da Microsoft, era utilizada por uma parcela pequena do corpo docente. Entre suas funcionalidades, trata-se de uma plataforma unificada de comunicação e colaboração, que combina bate-papo, videoconferências, armazenamento de arquivos e integração de aplicativos no local de trabalho.

Desde então, a plataforma Teams passou a ser a forma na qual os professores deram início às suas atividades docentes, ou seja, às aulas remotas, no mesmo horário praticado pelas aulas presenciais. Com essa nova prática, as reações dos docentes foram as que mais impactaram o cenário disruptivo. Na verdade, emergiu uma gama muito variada de comportamentos. Surgiram exemplos de professores que adotaram com conforto e desenvoltura o uso da plataforma digital, bem como profissionais que resistiram à proposta, pois sentiam mais segurança em se comunicar com seus alunos por intermédio de seus e-mails pessoais.

Oportuno observar que os órgãos de gestão da universidade se desdobraram em preparar documentos orientadores, bem como instrumentos de acompanhamento. Mas, não houve tempo para os docentes se prepararem. A cada dia os professores fizeram avanços, passo a passo, rumo ao uso adequado das ferramentas. Os momentos de formação dos docentes para o manuseio dos recursos tecnológicos disponíveis se proliferaram. Mesmo assim, foi preciso um movimento de solidariedade entre os professores, no sentido de se ampararem no tocante ao domínio de novos conhecimentos.

Os alunos também foram foco de atenção na nova dinâmica de aulas remotas. Foi feito um levantamento para identificar os estudantes sem recursos tecnológicos necessários para acompanharem as aulas remotas. Para eles foram destinados notebooks, a título de empréstimo.

Os planos de aula e os processos avaliativos tiveram que ser redefinidos, em função dos novos cenários online. Os planos com uma nova sistemática avaliativa passaram a ficar bem acessíveis para a gestão acadêmica e para os estudantes. O sistema de notas permaneceu e as aulas remotas passaram a ser gravadas. O calendário escolar sofreu pequenas alterações para atender aos dispositivos legais emanados das agências governamentais.

As aulas desenvolvidas pela segunda autora deste artigo foram implementadas em um Programa de Pós-graduação da Universidade que atende a pesquisadores de doutorado e 
mestrado acadêmico. As aulas semanais presenciais de três horas, no início do isolamento, foram substituídas por encontros remotos pelo Teams, no mesmo dia, horário e carga horária.

A dinâmica das aulas remotas ancorada na premissa dialógica foi mantida e as atividades didático pedagógicas tiveram continuidade com algumas adaptações. As aulas presenciais eram preparadas com a indicação de leituras sobre a temática a ser tratada. Os alunos eram orientados a anotar questionamentos relacionados aos seus referenciais de pesquisa, a partir das leituras feitas. Durantes as aulas remotas, esses questionamentos vinham à tona e as conversas se desenrolavam com muita animação. Dessa forma, os conceitos eram construídos, expandidos e até relacionados com outros constructos. A condição de estar ocupando uma plataforma da web, durante a aula online, facilitou a prática de consultas e compartilhamento de informações, materiais e conteúdos hipermidiáticos entre todos. Nas aulas presenciais, já havia o hábito de compartilhar informações por meio de um grupo criado no aplicativo WhatsApp. Nas aulas remotas, passou-se a enriquecer esse compartilhamento com a projeção dos conteúdos dos endereços pesquisados.

Um aspecto da interatividade com os alunos durante as aulas online teve que ser reconstruído: nas aulas presenciais a proximidade física oferecia a possibilidade de ler os sinais corporais dos alunos para direcionar a discussão, a fim de proporcionar processos reflexivos; durante as aulas remotas, esse simples expediente teve que ser substituído pela intensificação dos diálogos. Nos anos de docência, essa professora tem aprendido a trabalhar com os significados dos alunos, bem como desenvolvido a compreensão que todos somos seres autopoiéticos (MATURANA e VARELA, 1995). Dessa concepção decorre sua prática pedagógica, a qual permite que o conhecimento seja desenvolvido de dentro para fora a partir dos significados pessoais.

Em função do aparato tecnológico, o percurso temático da disciplina foi adaptado e alguns seminários foram incluídos, preparados pelos alunos a partir de leituras selecionadas. Os seminários resultaram em oportunidade de debater o assunto e, por vezes, foi possível contar com a presença de autores dos textos lidos nas aulas online. Dessa experiência resultou a preparação de um e-book para retratar a rica experiência vivenciada.

\section{Considerações finais}

Tendo em vista os desdobramentos do cenário da pandemia da COVID-19 no ensino superior, esse artigo procurou refletir sobre os problemas impostos a estudantes e docentes, bem como seus enfrentamentos. 
No tocante à abordagem metodológica, o artigo consubstancia-se como um relato analítico das ações educacionais desenvolvidas por duas docentes, autoras do presente artigo, em duas universidades sediadas no estado de São Paulo: uma pública federal e uma comunitária de caráter confessional.

O quadro teórico de referência deste relato analítico apoia-se na premissa dialógica, com destaque para dois conceitos: a ação comunicativa habermasiana e o dialogismo bakhtiniano.

A pandemia da COVID-19 acabou por induzir as instituições de ensino a ações remotas nos cursos presenciais (BRASIL, 2020 - Parecer CNE/CP n. ${ }^{\circ}$ 5). Nesse contexto, a reflexão ora apresentada adverte para o fato de que a racionalidade instrumental tem, em grande medida, amparado diversas ações educacionais, no âmbito do ensino superior. Com base na racionalidade instrumental, muitas instituições de ensino superior, sobretudo as de caráter patronal, têm visto a modalidade de educação a distância como estratégia para economia de custo (PESCE, 2010). O mesmo se aplica agora, no contexto da pandemia da COVID-19, que acabou por impulsionar o recrudescimento do ensino remoto.

Os resultados da institucionalização da educação a distância, com base em tal premissa, têm sido desastrosos, como aponta a literatura (BARRETO, 2001, 2006; MARFIM e PESCE, 2019; PESCE, 2010; ZUIN, 2006, dentre outros estudos). O mesmo cenário desolador se apresenta em relação a cursos presenciais que, em função da pandemia da COVID-19, têm utilizado as Tecnologias Digitais da Informação e Comunicação (TDIC) preocupados com a economia de gastos, mesmo que em detrimento da qualidade social (CONAE, 2018) dos processos formativos.

Por meio dela - da racionalidade instrumental -, o mundo da vida dos atores sociais diretamente envolvidos nos processos formativos acaba por ser colonizado pelo sistema educacional. Em refuta à racionalidade instrumental, hegemônica nas organizações societárias capitalistas, nelas incluso o sistema educacional, o presente artigo buscou apresentar um relato analítico de algumas ações desenvolvidas por ambas as autoras, junto a estudantes do ensino superior, balizadas na premissa dialógica, em respeito ao mundo da vida dos sujeitos sociais participantes das aludidas ações educacionais.

Amparadas na premissa dialógica, as ações formativas ora relatadas procuraram dar atenção à materialidade histórica dos estudantes e professores, ao mundo da vida forjado no cotidiano, buscando engendrar relações atentas à polifonia e à polissemia dos sujeitos sociais diretamente envolvidos nos processos formativos: professores e estudantes. 
Os desafios são muitos, sobretudo os relacionados ao bem-estar dos atores sociais diretamente envolvidos nos processos formativos: estudantes, professores, gestores, técnicos educacionais. Mas, em que pesem os inúmeros obstáculos macroestruturais - que se refletem nas condições materiais dos sujeitos sociais, mormente dos estudantes -, a premissa dialógica garante que a atitude docente se ampare no acolhimento e na abertura ao novo, sempre em devir. Atitude essa que se situa como primordial ao enfrentamento dos conflitos educacionais emanados do contexto da pandemia da COVID-19.

\section{REFERÊNCIAS}

BAKHTIN, Michail. (VOLOCHINOV). Marxismo e filosofia da linguagem. 8 ed. Trad. M. Lahud e Y. F. Vieira. São Paulo: Hucitec, 1997a.

BAKHTIN, Michail. Estética da criação verbal. 2 ed. Trad. M. E. G. Pereira. São Paulo: Martins Fontes, 1997b.

BAKHTIN, Michail. Para uma filosofia do ato responsável. Trad. V. Miotello e C. A. Faraco. São Carlos: Pedro e João Editores, 2010.

BARRETO, Raquel Goulart. As políticas de formação de professores: novas tecnologias e educação a distância. In: BARRETO, Raquel Goulart (org.). Tecnologias educacionais e educação a distância: avaliando políticas e práticas. Rio de Janeiro: Quartet, 2001, p 10-28.

BARRETO, Raquel Goulart. Política de educação a distância: a flexibilização estratégica. In: LOPES, Alice Casimiro; MACEDO, Elizabeth (Orgs.). Políticas de currículo em múltiplos contextos. São Paulo: Cortez, 2006, p. 187-204. (Série cultura, memórias e currículo; v. 7)

BRASIL. Ministério da Educação. Gabinete do ministro. Portaria n. 2.117, de 6 dez. 2019. Dispõe sobre a oferta de carga horária na modalidade de Ensino a Distância - EaD em cursos de graduação presenciais ofertados por Instituições de Educação Superior - IES pertencentes ao Sistema Federal de Ensino. Disponível em: https://www.in.gov.br/en/web/dou/-/portaria-n2.117-de-6-de-dezembro-de-2019-232670913 Acesso em: 30 set. 2020.

BRASIL. Ministério da Educação. Conselho Nacional da Educação. Parecer $C N E / C P N^{o}$ 5/2020. Reorganização do Calendário Escolar e da possibilidade de cômputo de atividades não presenciais para fins de cumprimento da carga horária mínima anual, em razão da Pandemia da COVID-19. Diário Oficial da União, Brasília, DF, 1 jun. 2020. Disponível em: http://portal.mec.gov.br/docman/marco-2020-pdf/144511-texto-referencia-reorganizacao-doscalendarios-escolares-pandemia-da-covid-19/file. Acesso em: 30 set. 2020.

CONFERÊNCIA NACIONAL DE EDUCAÇÃO (CONAE). Documento Referência. Brasília, DF: MEC, 2018. Disponível em: http://conae.mec.gov.br/images/pdf/doc referencia_conae_2018.pdf. Acesso em: 30 set. 2020. 
DIAS, Érika; PINTO, Fátima Cunha Ferreira. A Educação e a COVID-19. Ensaio: Aval. Pol. Públ. Educ., Rio de Janeiro, v.28, n.108, p. 545-554, jul./set. 2020. Disponível em: https://www.scielo.br/pdf/ensaio/v28n108/1809-4465-ensaio-28-108-0545.pdf. Acesso em: 30 set. 2020.

FREIRE, Paulo. Extensão ou comunicação? 7 ed. Rio de Janeiro: Paz e Terra, 1983.

FREIRE, Paulo. Pedagogia da autonomia: saberes necessários à prática educativa. 6 ed. São Paulo: Paz e Terra, 1997.

FREIRE, Paulo. Educação e mudança. 24 ed. Rio de Janeiro: Paz e Terra, 2001.

FREIRE, Paulo; SHOR, Ira. Medo e ousadia: o cotidiano do professor. 7 ed. São Paulo: Paz e Terra, 1997.

FREITAG, Bárbara. Dialogando com Jürgen Habermas. Rio de Janeiro: Tempo Brasileiro, 2005.

HABERMAS, Jürgen. Teoría de la acción comunicativa I. Trad. Manuel Jimenez Redondo. Madrid: Taurus, 1987.

HABERMAS, Jürgen. Pensamento pós-metafísico: estudos filosóficos. Trad. F. B. Siebenichler. Rio de Janeiro: Tempo Brasileiro, 1990.

HABERMAS, Jürgen. On the pragmatics of communication. Cambridge: The MIT Press, 1998.

HABERMAS, Jürgen. De l'éthique de la discussion. Trad. Mark Hunyadi. Paris: Flammarion, Centre National des Lettres, 1999.

HABERMAS, Jürgen. Agir comunicativo e razão descentralizada. Trad. L. Aragão. Revisão D. C. da Silva. Rio de Janeiro: Tempo Brasileiro, 2002.

HABERMAS, Jürgen. Consciência moral e agir comunicativo. 2 ed. Trad. G. A. de Almeida. Rio de Janeiro: Tempo Brasileiro, 2003.

MAIA, Berta Rodrigues; DIAS, Paulo César. Ansiedade, depressão e estresse em estudantes universitários: o impacto da COVID-19. Estudos de Psicologia, Campinas, v. 37, e 200067, 2020. Disponível em: https://www.scielo.br/pdf/estpsi/v37/1678-9865-estpsi-37e200067.pdf. Acesso em: 30 set. 2020.

MARFIM, Lucas; PESCE, Lucila. Trabalho, formação de professores e integração das TDIC às práticas educativas: para além da racionalidade tecnológica. Arquivos Analíticos de Políticas Educativas, v. 27, n. 89, p. 1-31, 2019. Disponível em: https://www.researchgate. net/publication/334972644_Trabalho_formacao_de_professores_e integracao_das_TDIC_as _ praticas_educativas_Para_alem_da_racionalidade_tecnologica Acesso em: 30 set. 2020. 
MATURANA, Humberto; VARELA, Francisco. A árvore do conhecimento: as bases biológicas do entendimento humano. Trad. Jonas Pereira dos Santos. Campinas: Editorial Psy II, 1995.

PESCE, Lucila. As contradições da institucionalização da educação a distância, pelo Estado, nas políticas de formação de educadores: resistência e superação. Revista HISTEDBR Online, Campinas/SP, v. 1, n. 26, p. 183-208, jun., 2007. Disponível em: https://www.fe. unicamp.br/pf-fe/publicacao/4991/art11_26.pdf Acesso em: 30 set. 2020.

PESCE, Lucila. Formação online de educadores sob enfoque dialógico: da racionalidade instrumental à racionalidade comunicativa. Revista Quaestio, v. 12, p. 25-61, jul. 2010. Disponível em: http://periodicos.uniso.br/ojs/index.php/quaestio/article/view/177/177 Acesso em: 30 set. 2020.

PESCE, Lucila. Avaliação da aprendizagem nos programas online de formação continuada de educadores. Estudos em Avaliação Educacional, São Paulo, v. 23, n. 51. p. 190-213, jan./abr., 2012. Disponível em: DOI: http://dx.doi.org/10.18222/eae235120121956 Acesso em: 30 set. 2020.

PESCE, Lucila. Políticas de formação inicial de professores, tecnologias e a construção social do tempo. EccoS, Revista Científica, São Paulo, v. 33, n. 01, p. 157-172, jan.-abril., 2014. Disponível em: http://www4.uninove.br/ojs/index.php/eccos/article/viewFile/3598/ 2721 Acesso em: 30 set. 2020.

PESCE, Lucila; HESSEL, Ana Maria Di Grado. Fundamentos ontológicos e epistemológicos da aprendizagem on-line. Educação e Cultura Contemporânea, Rio de Janeiro, v. 16, n. 43, 2019, p. 11-29. Disponível em: http://periodicos.estacio.br/index.php/reeduc/article/view/ 5871/47965982 Acesso em: 30 set. 2020.

SANTAELLA, Lúcia. O ciberespaço e sua linguagem: a hipermídia. In: SANTAELLA, Lúcia. Navegar no ciberespaço: o perfil cognitivo do leitor imersivo. São Paulo: Paulus, 2004, p. 37-53.

UNESCO. A Comissão Futuros da Educação da Unesco apela ao planejamento antecipado contra o aumento das desigualdades após a COVID-19. Paris: Unesco, 16 abr. 2020.

Disponível em: https://pt.unesco.org/news/comissao-futuros-da-educacao-da-unesco-apelaao-planejamento-antecipado-o-aumento-das Acesso em: 30 set. 2020.

VELOSO, Maristela Midlej Silva de Araújo; BONILLA, Maria Helena Silveira. O professor e a autoria em tempos de cibercultura: a rede da criação dos atos de currículo. Rev. Bras.

Educ. [online]. Rio de Janeiro, v. 23, e230026, p. 1-23, maio, 2018. Disponível em:

http://www.scielo.br/scielo.php?pid=S1413-782018000100220\&script=sci_abstract\&tlng=pt. Acesso em: 30 set. 2020.

ZUIN, Antônio Álvaro. Educação a distância ou educação distante? O Programa Universidade Aberta do Brasil, o tutor e o professor virtual. Educação e Sociedade [online], Campinas/SP, v. 27, n. 96, p.935-954, p. 935-954, 2006. Disponível em:

https://doi.org/10.1590/S0101-73302006000300014. Acesso em: 30 set. 2020. 


\section{SOBRE AS AUTORAS:}

\section{Lucila Pesce}

Doutora em Educação: Currículo, PUC-SP, com pós-doutorado em Filosofia e História da Educação, UNICAMP; Universidade Federal de São Paulo, UNIFESP - Brasil; Programa de Pós-Graduação em Educação - PPGE, UNIFESP; Líder do Grupo de Pesquisa Linguagem, Educação e Cibercultura - LEC. E-mail: lucila.pesce@ unifesp.br

(iD https://orcid.org/0000-0002-2562-2012

\section{Ana Maria Di Grado Hessel}

Doutora em Educação: Currículo, PUC-SP; Pontifícia Universidade Católica de São Paulo Brasil; Programa de Pós-Graduação em Tecnologias da Inteligência e Design Digital - TIDD; Vice-líder do Grupo de Pesquisa em Tecnologias Educacionais - GEPTED. E-mail: anadigrado@pucsp.br

iD https://orcid.org/0000-0003-4776-7754

Recebido em: 15 de outubro de 2020. 